\title{
Experimental investigation on spray characteristics of a coal to liquid blended fuel under different injection conditions
}

\author{
Chao Zheng, Hucheng Zhang, Zhao Lv, Zhiwei Jin, Xinqi Qiao* \\ Key Laboratory of Power Machinery and Engineering of Ministry of Education, School of \\ Mechanical Engineering, Shanghai Jiao Tong University, Shanghai, P.R.China \\ ${ }^{*}$ Corresponding author email : qiaoxinqi@sjtu.edu.cn
}

\begin{abstract}
In this work, coal to liquid blended fuel (DBCL) is composed of coal direct liquefied diesel oil and coal indirect liquefied diesel oil in the mass ratio of 7:3. The aim of this study is to explore the spray and atomization characteristics of DBCL with different injection pressure, injection pulse width and ambient pressure. The spray macroscopic parameters are analyzed by highspeed photography and MATLAB. The results show that the spray penetration and spray area increase with the increase of injection pressure. The spray cone angle also increases as injection pressure increases in the late injection stage. Changing the fuel injection pulse width has no obvious effect on the spray penetration, spray area and spray cone angle. The spray penetration and spray area increase with the increase of injection pulse width. The increase of ambient pressure leads to an increase in motion resistance, resulting in reduced spray penetration and area. However, ambient pressure has little effect on the spray cone angle.
\end{abstract}

\section{Keywords}

coal to liquid blended fuel, spray, injection pressure, ambient pressure, injection pulse width.

\section{Introduction}

The current situation of energy crisis has led the researcher to extract the fuel efficiency of the diesel engine ${ }^{[1]}$, and the high pressure common rail injection is an effective means to improve fuel efficiency ${ }^{[2]}$. There are four stages during the combustion period. they are the ignition delay, rapid combustion, slow combustion and afterburning, and the first two stages are the main contribution period of fuel oil ${ }^{[3]}$. The high voltage common rail could effectively realize the controllable combustion process by controlling the parameters of the spray, such as the spray Angle, the spray area, the spray velocity and so on. At the same time, the parameter of the spray can be effectively implemented in the thick burning in turn which is also called two stage combustion by Professor Kamito ${ }^{[5]}$. The concentration of concentrated mixture gas is controlled, especially the formation of strong mixture, and the heat and active material required for the thin mixture is obtained to reduce the purpose of NOx and PM emissions. The coal to liquid blended fuel (DBCL) is composed of coal direct liquefied diesel oil and coal indirect liquefied diesel oil was used as test fuels in this paper. Naphthenes are the main components of direct liquefied diesel oil, so it is low sulfur, low nitrogen, high density, low concentration and low decane. Indirect liquefied diesel is mainly composed of n-alkanes, and it is low density, high concentration and high decane. The diesel of the two processes has good complementarity, and the direct liquefication and indirect liquefication of diesel oil to solve the energy problem are of great significance ${ }^{[6]}$.

In this paper, the formation parameters of fuel injection of direct liquefaction and indirect liquefaction diesel mixed with 7:3 ratio in different fuel injection parameters are studied, so as to make a preliminary study on the formation of combustion mixture.

\section{Material and Methods}

According to the standard of automotive diesel, the physicochemical properties of diesel were analyzed. The physicochemical properties of DBCL were investigated and compared with that 
of $\mathrm{G} 6$ fuel ${ }^{[4]}$. The data are shown in Table 1. As can be seen from Table 1, DBCL has the following characteristics: (1) Good color and lustre. DBCL's color are colorless and transparent; (2) The corrosion is small. Sulfur content $<0.2$, and detected acidity $<0.2$; (3) Stability. Since DBCL has little or no restless components such as olefins, polycyclic aromatic hydrocarbons, and sulfur and oxygen compounds, the total insoluble matter is not high. (4) Good wear resistance and lubricity: DBCL lubricity wear trace diameter is small.

Table 1 - Physical properties of test fuel

\begin{tabular}{c|cc}
\hline Parameter & $\mathrm{G} 6$ & $\mathrm{DBCL}$ \\
\hline Density $\left(20^{\circ} \mathrm{C}\right)\left(\mathrm{g} / \mathrm{cm}^{3}\right)$ & 0.838 & 0.8157 \\
Density $\left(30^{\circ} \mathrm{C}\right)\left(\mathrm{g} / \mathrm{cm}^{3}\right)$ & 0.8311 & 0.8086 \\
Density $\left(60^{\circ} \mathrm{C}\right)\left(\mathrm{g} / \mathrm{cm}^{3}\right)$ & 0.8101 & 0.7871 \\
Sulphur content $(\mathrm{ug} / \mathrm{g})$ & 5.24 & $<0.2$ \\
Acidity $(\mathrm{mgKOH} / 100 \mathrm{ml})$ & 4.1 & $<0.2$ \\
Kinematic viscosity $\left(20^{\circ} \mathrm{C}\right)\left(\mathrm{mm}^{2} / \mathrm{s}\right)$ & 4.6972 & 2.7995 \\
Surface tension $\left(20^{\circ} \mathrm{C}\right)(\mathrm{mN} / \mathrm{m})$ & 27.86 & 26.02 \\
Surface tension $\left(50^{\circ} \mathrm{C}\right)(\mathrm{mN} / \mathrm{m})$ & 25.14 & 23.56 \\
Surface tension $\left(90^{\circ} \mathrm{C}\right)(\mathrm{mN} / \mathrm{m})$ & 22.99 & 20.79 \\
Lubricating wear mark diameter $\left(60^{\circ} \mathrm{C}\right) / \mathrm{um}$ & 400 & 335 \\
FAME $($ volume fraction $) / \%$ & 0.1 & $<0.1$ \\
Initial boiling point $/{ }^{\circ} \mathrm{C}$ & 168.5 & 178.1 \\
$10 \%$ & 227.6 & 194.0 \\
$50 \%$ & 271.0 & 219.3 \\
$90 \%$ & 325.1 & 291.2 \\
Dry point $/{ }^{\circ} \mathrm{C}$ & 346.2 & 334.0 \\
Total aromatic hydrocarbon of distillate $/ \%$ & 24.8 & 1.4
\end{tabular}

The structure diagram of the research test bench is shown in Figure 1. The test system mainly consists of three parts: the high pressure common rail injection system, the constant volume bomb system and the high speed photography system. The high pressure common rail injection system produces high pressure fuel and completes fuel injection through a single hole injector. The constant volume bomb system provides a certain volume of back pressure for spray. The high speed photography system is responsible for capturing and storing the spray photos. The process of changing the fuel in the test is very important. After the fuel is changed, it is necessary to carry out the oil discharge operation in order to ensure that all the fuel is changed in the oil circuit. When the oil discharge is completed, nitrogen at a certain pressure is filled into the constant volume bomb, and the test can be started after the pressure value stabilizes. The injector is a single hole injector with a diameter of $0.28 \mathrm{~mm}$. 


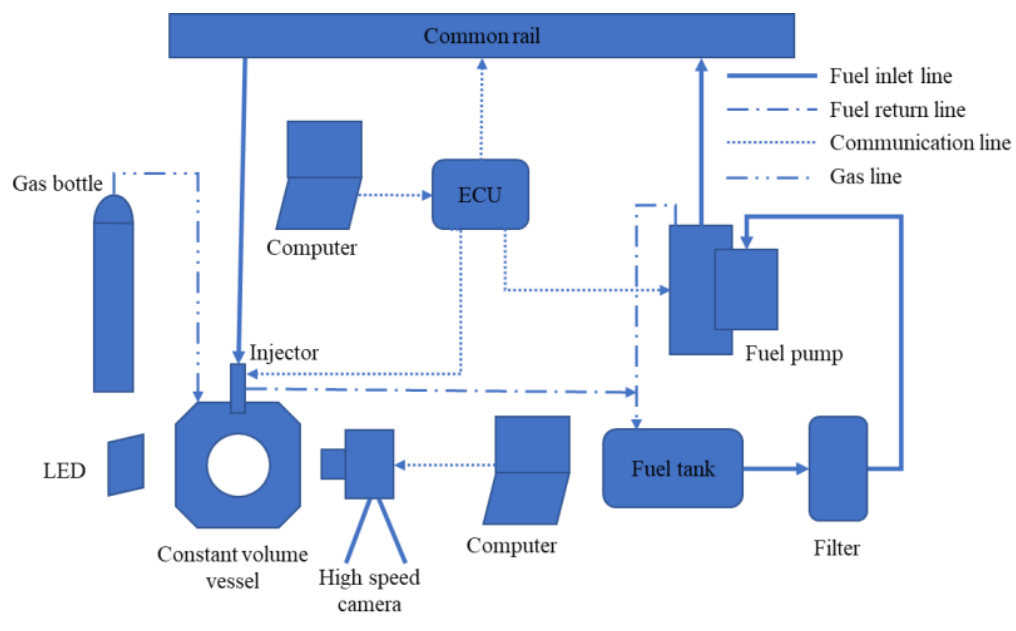

Figure 1 Block diagram of fuel spray test system

In addition, the test also need to use micro spray test equipment high speed spray particle size analyzer, the particle size analyzer of the spray particle size measurement based on laser diffraction method. The basic principle is: the laser diffraction occurs when it passed spray particle, and the diffraction light deviates from the direct light Angle is inversely proportional to the particle size, different size particles of the diffraction of light falls on different positions, therefore the particle size can be obtained according to the position of the diffraction of light. The table 2 shows the specifications and parameters of the spray test equipment in this test.

Table 2 -Equipment of fuel spray test

\begin{tabular}{c|c}
\hline Devicename & Specification parameter \\
\hline Fuel injection pump bench & CRI-250 \\
Constant volume bomb & visible range: $100 \mathrm{~mm}$, The highest \\
High-speed camera & pressure:35MPa \\
Memrecam HX-6 \\
High speed spray particle size analyzer & Spraylink particle size range:0.1um- \\
Oil atomizer & $2080 \mathrm{um}$ \\
& $1 \times 0.28 \mathrm{~mm}$
\end{tabular}

\section{Results and Discussion}

In the process of injector injection, the spray morphology is shown in Fig. 2. This paper takes the injector axis as the axis, and defines the axis distance between the nozzle front end and the spray front as the spray penetration distance $(\mathrm{L})$. The average growth rate of penetration distance in the time interval between two adjacent photos was defined as the spray front velocity. The spray cone angle is defined as the angle between the spray contour and the spray profile at the $1 / 3$ penetration distance. The spray area is the area inside the envelope of the outer contour of the spray. Time zero is the time of fuel is ejected orifice. 


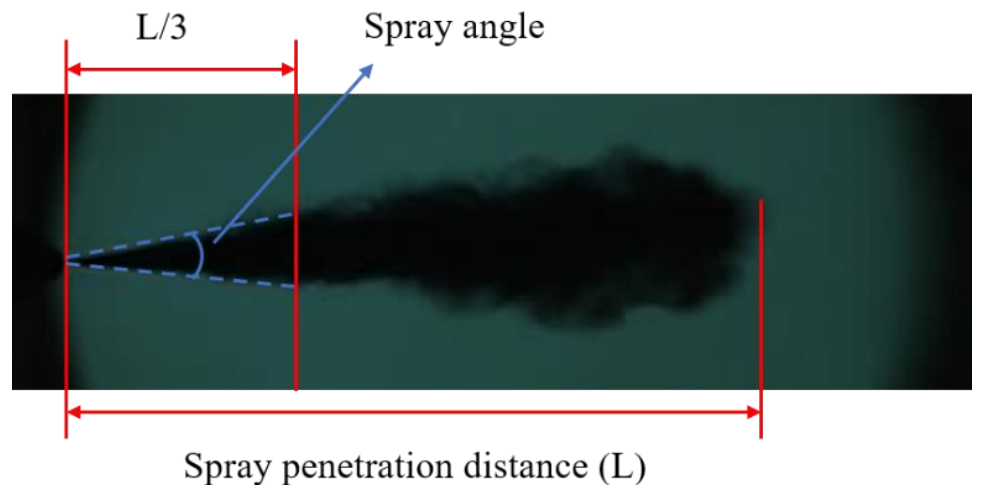

Figure 2 Definition of spray parameters

1. Under the condition of backpressure $2.5 \mathrm{MPa}$ and rail pressure $120 \mathrm{MPa}$, the effects of fuel injection pulse width on fuel spray penetration distance and spray front velocity are as follows: (1)The effect of injection pulse width on spray penetration: In the early stage of fuel injection, the spray penetration distance of fuel varies little with the pulse width of fuel injection, and the difference in penetration gradually appears in the late injection stage. The smaller the injection pulse width, the shorter the spray penetration distance is, as shown in Figure 3-a. The reason for this phenomenon is that the shorter the pulse width and the earlier the end of the fuel injection, the less momentum can be gained without subsequent fuel replenish, so the penetration distance decreases.

(2)The effect of injection pulse width on the velocity of the spray front: Before the end of the fuel injection, the fuel front velocity is not significantly affected by the injection pulse width. However, in the time period between $0.75 \mathrm{~ms}$ and the forward boundary of the spray front, the long front width of the spray front is larger than that of the short pulse width, as shown in Figure $3-\mathrm{B}$. This is consistent with the influence factor of penetration distance, which is caused by fuel end injection and spray momentum reduction.

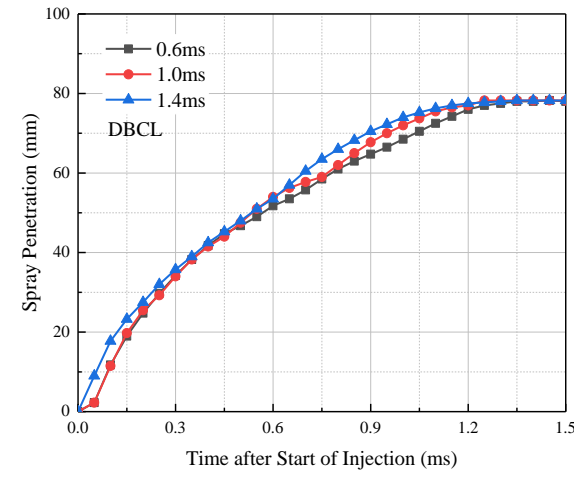

a) Spray Penetration

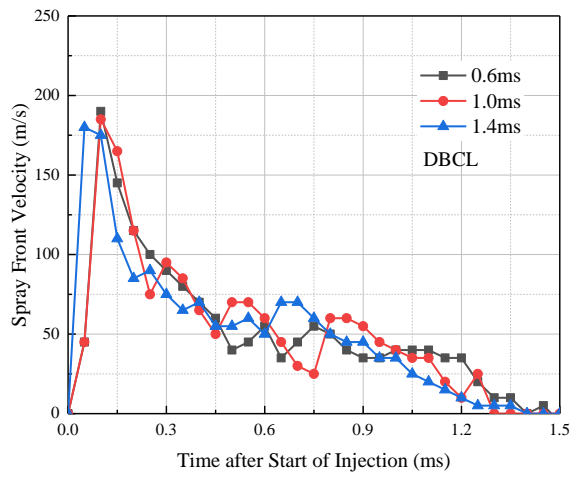

b) Spray Front Velocity

Figure 3 Effect of energizing time on spray penetration and spray front velocity (ambient pressure: 2.5MPa, rail pressure: $120 \mathrm{MPa}$ )

2. Effect of injection pulse width on spray area and spray cone angle: 
(1) Spray area: The spray area is very similar to the spray pulse width and the spray penetration distance, as shown in Figure 4-A. In the most part of the injection time, the injection pulse width has no effect on the spray area of the fuel; the spray area increases with the increase of injection pulse width in the late injection stage. At the end of the injection stage, when the injection duration is short, the spray continues to move forward, and the spray area decreases naturally compared with the longer pulse width.

(2) Spray cone angle: As shown in Fig. 4-b, the fuel injection pulse width is different, and the spray cone angle is not very different. Generally speaking, the spray cone angle is determined by the radial diffusion of fuel. Under normal fuel injection conditions, the same fuel property is the same, and the back pressure and rail pressure are the same. The pulse width only affects the end time and subsequent spray. Therefore, there is little difference in the spray cone angle under different pulse width in the early stage of fuel injection.

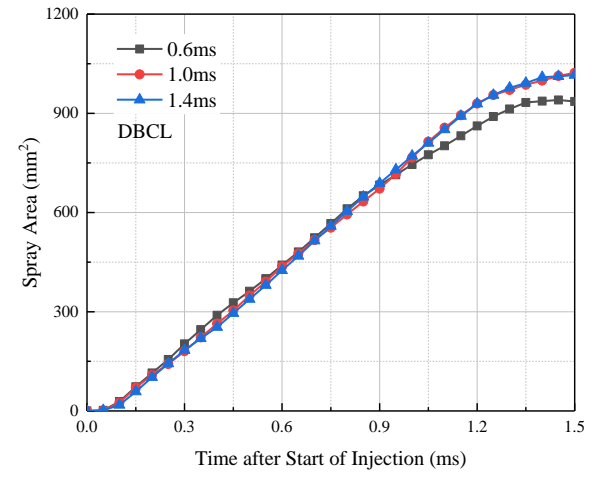

a) Spray area

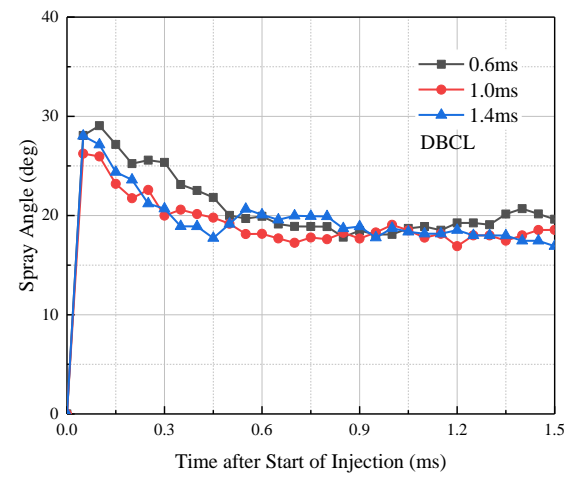

b) Spray angle

Figure 4 Effect of energizing time on spray area and spray angle (ambient pressure: 2.5MPa, rail pressure: $120 \mathrm{MPa})$

3. The effect of fuel injection pressure on fuel spray penetration and spray front velocity:

When the injector structure, injection pulse width and ambient backpressure are the same, the higher the injection pressure, the greater the initial momentum obtained when the fuel is away from the nozzle, and more fuel is added to the spray in the same time. Therefore, the forward movement of the spray is faster and the penetration distance is longer, as shown in figure 5a. The effect of rail pressure on the velocity of the spray front is stronger than that of the pulse width. The maximum velocity of the spray front increases with the increase of rail pressure, as shown in figure 5-b. The reason is the same as the spray penetration distance. The velocity difference of the spray front decreases at the late stage of injection under different rail pressures. This is because the air resistance is proportional to the the square of velocity, and the faster the velocity decreases, the faster the convergence is. 


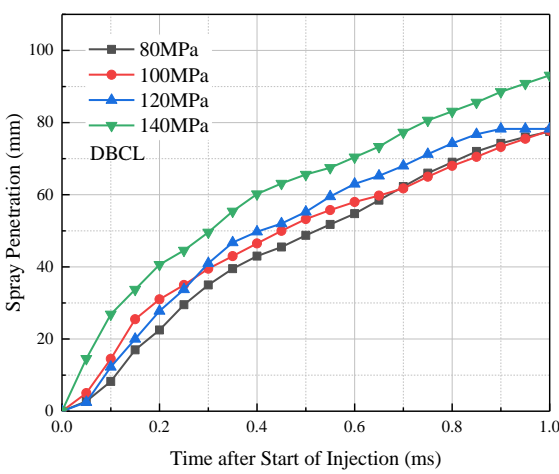

a) spray penetration

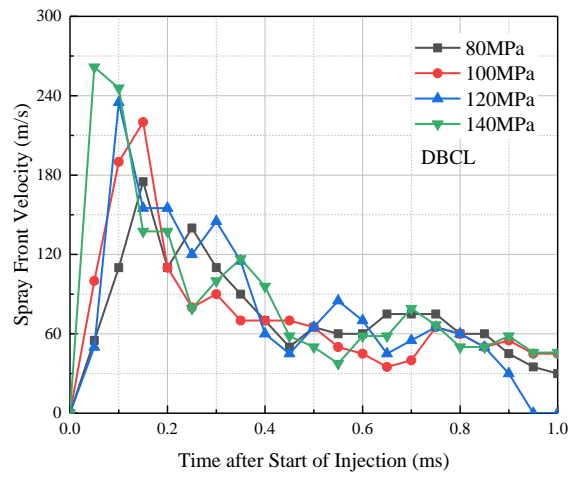

b) spray front velocity

Figure 5 Effect of rail pressure on spray penetration and spray front velocity (ambient pressure: $1.5 \mathrm{MPa}$, energizing time: $1.0 \mathrm{~ms}$ )

4. The effect of environmental backpressure on spray penetration and spray front velocity:

As shown in figure 6, under the same injection pressure and pulse width and fuel injector structure, the overall trend of fuel spray penetration distance is: with the increase of ambient back pressure, the spray penetration distance decreases in turn. The volume of fixed volume bomb is constant, and the internal gas temperature is basically unchanged. Therefore, the higher the backpressure is, the greater the density of the ambient gas. The greater the resistance of the fuel spray during the forward motion, the smaller the natural penetration of the spray. At the late stage of injection, the front end of the spray is strengthened by the influence of ambient gases, and the influence of the back pressure is beginning to show. The viscosity and surface tension of DBCL are smaller, and the oil droplets break earlier and are more strongly entrained by gas. The change of gas density due to backpressure changes also affects the forward velocity of the spray. When the back pressure is high, the motion resistance is large, leading to a corresponding decrease in the velocity of the spray front.

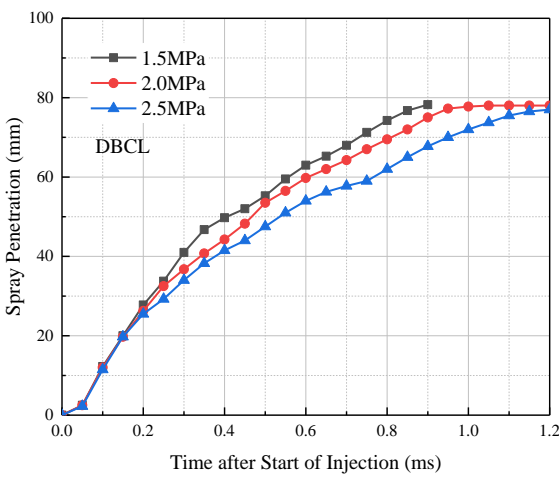

a) spray penetration

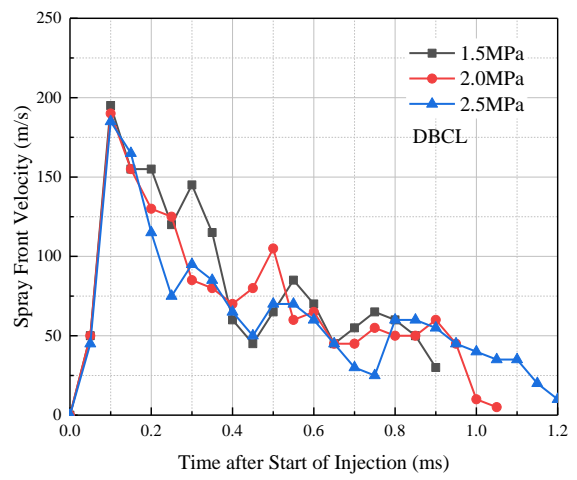

b) spray front velocity

Figure 6 Effect of ambient pressure on spray penetration and spray front velocity (rail pressure: 120MPa, energizing time: $1.0 \mathrm{~ms}$ )

5. The effect of ambient backpressure on fuel spray area: 
The higher the backpressure, the smaller the spray area, and the difference is more obvious with the extension of time. The diffusion resistance of spray increases with the increase of back pressure, so the spray area is reduced, as shown in figure 7-a. The effect of ambient backpressure on fuel spray cone angle is shown in figure 7-b. Correlation studies show that the increase of ambient gas density will lead to the contraction of spray, thus reducing the spray cone angle. The spray cone angle of DBCL increases slightly with the increase of back pressure, and the viscosity and surface tension of fuel are smaller. The spray oil beam is more easily broken when it moves axially, and is more sensitive to the ambient gas entrainment and disturbance. Therefore, it is more sensitive to the change of back pressure. When the back pressure increases, the axial movement of the spray is hindered more than the radial compression, so the spray cone angle increases.

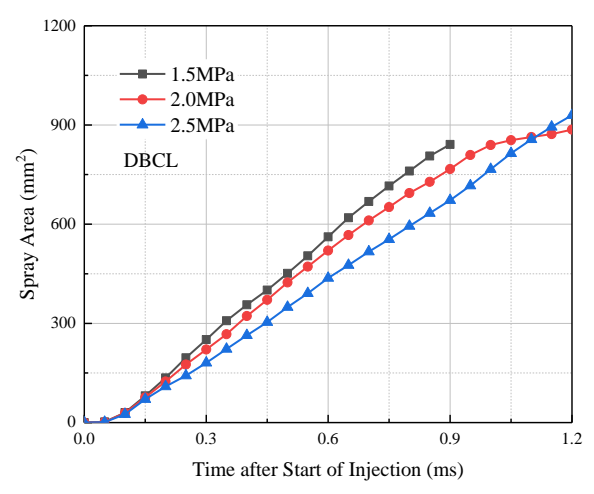

a) Spray area

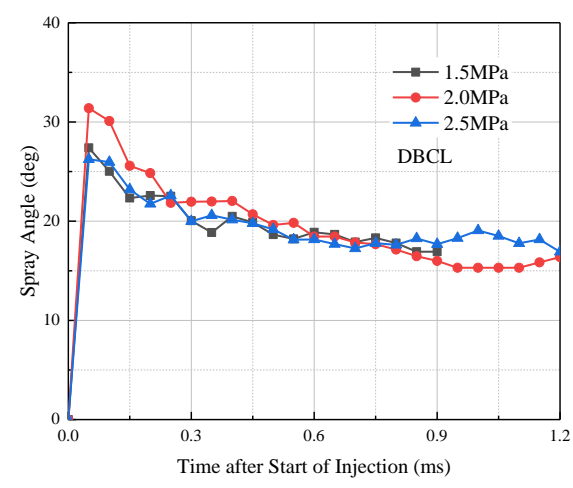

b) Spray angle

Figure 7 Effect of ambient pressure on spray area and spray angle (rail pressure: 120MPa, energizing time: $1.0 \mathrm{~ms})$

\section{Conclusions}

In this paper, the effects of injection pulse width, fuel injection pressure and ambient backpressure on the spray characteristics of DBCL are studied.

(1) At the early stage of injection, the influence of injection pulse width on penetration distance and velocity of spray front is not obvious. The shorter the injection pulse width is, the shorter the spray penetration distance is, and the longer the pulse width is, the greater the velocity of the spray front is than the short pulse width. The spray area also has the same rule. The longer the pulse duration, the larger the spray area. Fuel injection pulse width has little effect on fuel spray cone angle.

(2) With the increase of injection pressure, the spray penetration distance and the spray front velocity increase significantly. The spray area and spray cone angle also increased with the increase of rail pressure.

(3) The spray penetration distance of fuel is not affected by the back pressure at the early stage of injection. The late injection stage decreases with the increase of back pressure. The high back pressure causes the density of the environment gas to increase and the resistance to spray movement increase, thus slowing the velocity of the spray front. The area of fuel spray decreases with the increase of back pressure. The spray area of different fuels is not significantly different from that of back pressure, but the effect on spray cone angle is somewhat different. The backpressure increases and the spray cone angle increases slightly. 
Under the experimental conditions, the backpressure on the fuel has little effect on the spray cone angle of fuel.

\section{Acknowledgments}

The authors would like to acknowledge the financial supports provided by the National Key Research and Development Project of China (No.2017YFE0130800) and the National Natural Science Foundation of China (No. 91741122).

\section{References}

[1] LI Haijun. Study on the characteristics of coal direct liquefaction diesel products [J]. Chemical Industry Times, 2015, 29(12): 37- 41.

[2] LI Kejian, CHENG Shifu, LIN Hualin, et al. Study anddevelopment of Shenhua direct coal liquefactiontechnology[J] . Clean Coal Technology, 2015, 21(1): 50- 55.

[3] IGO R Micael AlvesUch ô aa, AFONSO Avelino Dantas Netoa, E R IN É IA da Silva Santosa, et al. Evaluation of lubricating properties of diesel based fuels micro emulsified with glycerin[J]. Materials Research, 2017, 20(S2): 701- 708

[4] General Administration of Quality Supervision,Inspection and Quarantine of the People's Republic of China,Standardization Administration of the People's Republic of China. Automobile Diesel Fuels(IV):GB 19147 2013[s]. Beijing: Standards Press of China,2013.

[5] RAKOPOULOS C D . DIMARATOS A M , GIAKOUMIS E G . Study of turbocharged diesel engine operation, pollutant emissions and combustion noise radiation during starting with bio - diesel or $n$ - butanol diesel fuel blends [ J ] . Applied Energy , 211, 8 8 (11):390 5 - 39 16 .

[6] YANG Z, CHU CY, WANG LJ. Effects of $\mathrm{H} 2$ addition on combustion and exhaust emissions in a diesel. engine [J]. Fuel, $2015,139:$ 90-197 . 